\title{
Encoding specificity and integration of word pairs
}

\author{
CHARLES DE VITO \\ Brooklyn College of the City University of New York, Brooklyn, New York 11210
}

\begin{abstract}
Word concreteness was shown to have a differential effect on recognition-cued recall differences for noun-adjective pairs in a variant of the Tulving and Thomson (1973) paradigm. Consistent with the notion of integration of concrete word pairs, cued recall was superior to recognition for concrete-concrete pairs, but not for other pair types. For abstract-concrete and abstract-abstract pairs the data suggested that recognition was superior to recall. For concrete-abstract pairs there was no difference between recognition and recall.
\end{abstract}

This study was prompted by an attempt to investigate further the notions of encoding specificity (Tulving \& Thomson, 1973) and integration of concrete word pairs (Begg, 1972). Olson (1974) showed that the superiority of cued recall over recognition performance, found by Tulving and Thomson (1973) only holds for items that could be categorized as noun-adjective pairs. Further examination of the noun-adjective pairs used suggests that they are all concrete-concrete items. Begg (1972) has shown that concrete-concrete adjective-noun pairs lead to better performance on a cued recall task as compared with a free recall task for the adjective members of the pairs. Begg argued that this is due to integrated memory structures aroused by concrete-concrete pairs.

This study investigates the hypothesis that one factor that affects recall-recognition differences is the degree of integration of a given pair of words. It is proposed that a pair of concrete words is more likely to be encoded as an integrated unit and performance on a cued recall task would be relatively better in the Tulving and Thomson paradigm. On the other hand, word pairs other than concrete-concrete tend not be encoded as integrated units and recognition would be expected to be better than recall.

\section{METHOD}

\section{Subjects}

The subjects were 15 volunteers from the introductory psychology course at Brooklyn College.

\section{Materials}

Three lists of noun-adjective pairs were constructed. One of the lists, the critical list, was used to test the experimental hypothesis while the other two were "priming" lists. The critical list was composed of both "high" and "low concreteness' nouns from the Paivio, Yuille, and Madigan (1968) norms, and "high" and "low concreteness' adjectives used by Begg (1972). Stimulus and response concreteness were varied factorially, yielding six pairs each of concrete-concrete (CC), concrete-abstract (CA), abstract-concrete (AC), and abstract-abstract (AA) words. An independent judge with experience in the verbal learning area selected pairs so that they were approximately equal in

Eric G. Heinemann sponsors this paper and takes full editorial responsibility for it. Requests for reprints should be sent to Charles DeVito, Department of Psychology, Brooklyn College of the City University of New York, Brooklyn, New York 11210. Special thanks to Solomon Weinstock for his comments on the manuscript and to Andrew Olson for his procedural assistance. meaningfulness, and so that each pair was relatively meaningful. The stimulus nouns were equated on "meaningfulness" (M) (Paivio, Yuille, \& Madigan, 1968) and frequency (F) (Kucera \& Francis, 1967) norms. The response adjectives were also equated on the $F$ norms. The CC pairs were: professor-HUNGRY, arm-DARK, village-WILD, hotel-ROUND, letter-COLORFUL, engine-SQUARE; with mean stimulus concreteness of 6.77 , mean stimulus $\mathrm{M}$ of 5.95 , mean stimulus $\mathrm{F}$ of 90.6 , and mean response $\mathrm{F}$ of 85.8 . The $\mathrm{CA}$ pairs were: hall-ADEQUATE, seat-COMMON, machine-ESSENTIAL, factory-PREVIOUS, newspaper-SUBTLE, army-APPARENT; with mean stimulus concreteness of 6.71 , mean stimulus $M$ of 6.16 , mean stimulus $F$ of 94 , and mean response $\mathrm{F}$ of 89.8 . The $\mathrm{AC}$ pairs were: soul-HOT, crime-BEAUTIFUL, knowledge-DEAD, freedomCRIPPLED, answer-FAT, occasion-WET; with mean stimulus concreteness of 2.82 , mean stimulus $M$ of 6.19 , mean stimulus $F$ of 89.6, and mean response $\mathrm{F}$ of 91.7. The AA pairs were: s h o ck-I M POS I B LE, direction-ADDI T I ONA L, chance-ORDINARY, theory-BASIC, charm-RATIONAL, expression-ABSOLUTE; with mean stimulus concreteness of 2.53 , mean stimulus $\mathrm{M}$ of 6.12 , mean stimulus $\mathrm{F}$ of 88.3 , and mean response $\mathrm{F}$ of 83.7 .

The four pair types for the priming lists were constructed from nouns taken from Paivio, Yuille, and Madigan (1968) and adjectives from Begg (1972) and Morris and Reid (1972).

Each pair was typed in the center of a $4 \times 6$ index card with the stimulus in lower case and the response member in upper case letters separated by a dash.

An additional list was constructed for the recognition task which contained the 24 response adjectives of the critical list randomly interspersed within a set of 72 distractor adjectives. The recognition sheet had four columns with 24 words per column. Half of the distractor words were judged low and half high on 'concreteness-imagery,' again with the concurrence of an independent judge. The mean $\mathrm{F}$ for the low distractor items was 85.3 , for the high it was 86.7. This list was constructed to avoid the possibility of lowered recognition performance as a function of semantic confusion which may occur in the generation-recognition procedure used by Tulving and Thomson (1973).

One recall sheet containing a random order of the 24 stimulus items was constructed for the critical list and for each of the priming lists.

\section{Procedure}

Each subject was given both priming lists and the critical list under a self-pacing routine. The two priming lists were randomly varied between first and second in the presentation sequence. For each subject there was a different random order for each list.

The subjects were instructed that they would be shown a set of index cards, one index card at a time, and that on each card there would be a capitalized word that they would be asked to remember later. They were also told that there would be another word accompanying the capitalized word, and the way they were to remember the capitalized word was to form a 
Table 1

Mean Recognition and Recall Performance for Each Pair Type

\begin{tabular}{lllllllll}
\hline \multicolumn{4}{c}{ Recognition } & \multicolumn{4}{c}{ Recall } \\
CC & CA & AC & AA & & CC & CA & AC & AA \\
\hline 3.87 & 2.87 & 4.33 & 2.6 & & 4.87 & 2.67 & 2.73 & 1.73 \\
\hline
\end{tabular}

mental picture representing both words. They were then given two examples: train-BLACK, and task-DIFFICULT. When it was clear that the instructions were understood, the cards for the first priming list were presented. Immediately afterwards, the subjects were given a three minute recall period in which they were asked to write down as many of the capitalized words as they could remember next to the appropriate stimulus words on the recall sheet. The presentation and recall procedure for the second priming list was the same. For the critical third list the presentation was the same, except that prior to cued recall the subjects were given the recognition list and told to write down on an accompanying yellow sheet of paper as many of the target words as they could find on the recognition list. They were given as much time as they desired for this task. When they were done, they were given the cued recall task.

\section{RESULTS AND DISCUSSION}

Performance on the recognition and cued recall task for the critical list was scored for number correct for each of the four pair types. Table 1 shows the mean values for each pair type in recognition and recall.

The data were subjected to a 2 by 2 by 2 (stimulus concreteness, response concreteness, task) repeated measures analysis of variance. The analysis indicated the significance of stimulus concreteness $[\mathrm{F}(1,14)=8.15$, $\mathrm{p}<.05]$; response concreteness $[\mathrm{F}(1,14)=37.17$, $\mathrm{p}<.01]$; stimulus by task interaction $[\mathrm{F}(1,14)=24.64$, $\mathrm{p}<.01]$; and the Stimulus by Response by Task interaction $[F(1,14)=9.84, p<.01]$. To analyze the three way interaction further, correlated $t$ tests were computed comparing the performance for each pair type on the recognition and cued recall tasks. For CC pairs, cued recall was superior to recognition $\mathrm{t}(14)=2.43$, $\mathrm{p}<.05$; for CA pairs, $\mathrm{t}(14)=.44$, no significant difference; for $\mathrm{AC}$ pairs, $\mathrm{t}(14)=6.5, \mathrm{p}<.01$, recognition was superior to recall; and for AA pairs, $t(14)=1.91, p<.10$. The results of the analysis for AA pairs possibly indicates a trend toward recognition superiority that was masked due to the relatively low levels of overall AA performance.

Despite the need for more refined methodological procedures, this experiment indicates the differential effectiveness of word concreteness in a variant of the Tulving and Thomson (1973) paradigm. For CC pairs, the results tend to support the original hypothesis. CC pairs were more effectively retrieved when a cued recall task was used as compared with a recognition task. The data tend to support the prediction that for $\mathrm{AC}$ and $\mathrm{AA}$ pairs recognition led to better retrieval than recall. For CA pairs, there was no difference between recognition and cued recall. This may indicate some degree of integration, possibly related to Begg's (1972) finding that abstract adjective-concrete noun pairs follow an integrated pattern for cued recall of adjectives.

\section{REFERENCES}

Begg, I. Recall of meaningful phrases. Journal of Verbal Learning and Verbal Behavior, 1972, 11, 431-439.

Kucera, H., \& Francis, W. N. Computational analysis of present-day American English. Providence: Brown University Press, 1967.

Morris, P. E., \& Reid, R. L. Imagery and the recall of adjectives and nouns from meaningful prose. Psychonomic Science, 1972, 27, 117-118.

Olson, A. M. The differential effects of syntactical pairings on cued recall and recognition. Bulletin of the Psychonomic Society, 1974, 3, 232-233.

Paivio, A., Yuille, J. C., \& Madigan, S. A. Concreteness, imagery, and meaningfulness values for 925 nouns. Journal of Experimental Psychology Monograph Supplement, 1968, 76.

Tulving, E. \& Thomson, D. M. Encoding specificity and retrieval processes in episodic memory. Psychological Review, 1973, 80, 358-372.

(Received for publication November 7, 1974.) 